\title{
Antimicrobial performance of mesoporous titania thin films: role of pore size, hydrophobicity, and antibiotic release
}

This article was published in the following Dove Press journal:

International Journal of Nanomedicine

10 March 2016

Number of times this article has been viewed

\author{
Saba Atefyekta' \\ Batur Ercan ${ }^{2,3}$ \\ Johan Karlsson' \\ Erik Taylor ${ }^{2}$ \\ Stanley Chung ${ }^{2}$ \\ Thomas J Webster ${ }^{1,4}$ \\ Martin Andersson' \\ 'Department of Chemistry and \\ Chemical Engineering, Chalmers \\ University of Technology, Gothenburg, \\ Sweden; ${ }^{2}$ Department of Chemical \\ Engineering, Northeastern University, \\ Boston, MA, USA; ${ }^{3}$ Department \\ of Metallurgical and Materials \\ Engineering, Middle East Technical \\ University, Ankara, Turkey; ${ }^{4}$ Center \\ of Excellence for Advanced Materials \\ Research, King Abdulaziz University, \\ Jeddah, Saudi Arabia
}

\begin{abstract}
Implant-associated infections are undesirable complications that might arise after implant surgery. If the infection is not prevented, it can lead to tremendous cost, trauma, and even life threatening conditions for the patient. Development of an implant coating loaded with antimicrobial substances would be an effective way to improve the success rate of implants. In this study, the in vitro efficacy of mesoporous titania thin films used as a novel antimicrobial release coating was evaluated. Mesoporous titania thin films with pore diameters of 4, 6, and $7 \mathrm{~nm}$ were synthesized using the evaporation-induced self-assembly method. The films were characterized and loaded with antimicrobial agents, including vancomycin, gentamicin, and daptomycin. Staphylococcus aureus and Pseudomonas aeruginosa were used to evaluate their effectiveness toward inhibiting bacterial colonization. Drug loading and delivery were studied using a quartz crystal microbalance with dissipation monitoring, which showed successful loading and release of the antibiotics from the surfaces. Results from counting bacterial colonyforming units showed reduced bacterial adhesion on the drug-loaded films. Interestingly, the presence of the pores alone had a desired effect on bacterial colonization, which can be attributed to the documented nanotopographical effect. In summary, this study provides significant promise for the use of mesoporous titania thin films for reducing implant infections.
\end{abstract}

Keywords: mesoporous titania, antibacterial, drug delivery, implant coating

\section{Introduction}

When implants are used to restore body functions, they provide a susceptible situation for microbial colonization. This is due to the fact that the body's defense systems are much weaker in the presence of a foreign material and that the surface of the implant generally is unable to suppress bacterial growth. ${ }^{1-3}$ These microbial colonizationderived infections, often referred to as biomaterial associated infections (BAI), are some of the most common causes of implant failure. ${ }^{4-7}$ For example, it has been observed that BAI occurs in $1.5 \%-2.5 \%$ of primary hip and knee replacements, which in $3.2 \%-5.6 \%$ of cases result in surgical revisions. ${ }^{8}$

The key pathogenic factor responsible for infection is the development of bacterial colonies embedded in a matrix, consisting of proteins, polysaccharides, and DNA, called a biofilm on the implant surface..$^{9-11}$ Such adhesive biofilms are very resistant toward the body's defense mechanisms and antibiotic treatments. ${ }^{1,12}$ The eradication of infections after the formation of a biofilm often necessitates removal and replacement of the implant, which results in high costs and trauma for the patient. ${ }^{13-15}$ Moreover, biofilms increase resistance to antibiotic treatments and raise the need for increased
Correspondence: Martin Andersson Department of Chemistry and Chemical Engineering, Chalmers University of Technology, Kemivägen I0, 4I 296

Gothenburg, Sweden

Tel +46 3I 7722966

$\mathrm{Fax}+4631160062$

Email martina@chalmers.se 
A

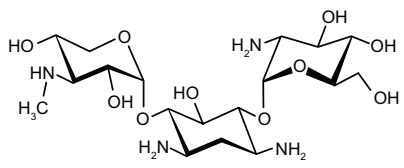

1

$<1 \mathrm{~nm}$
B

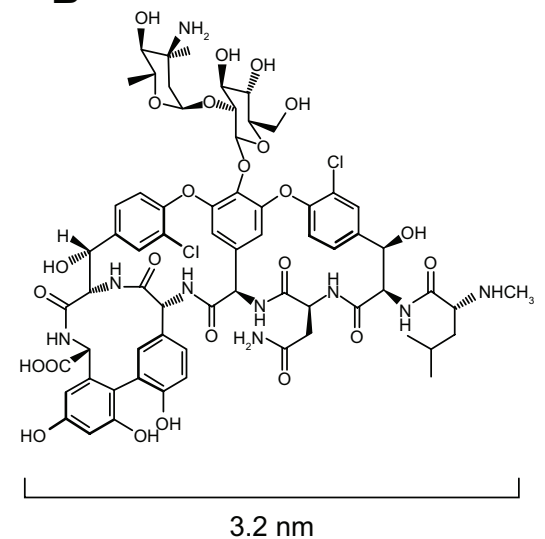

C

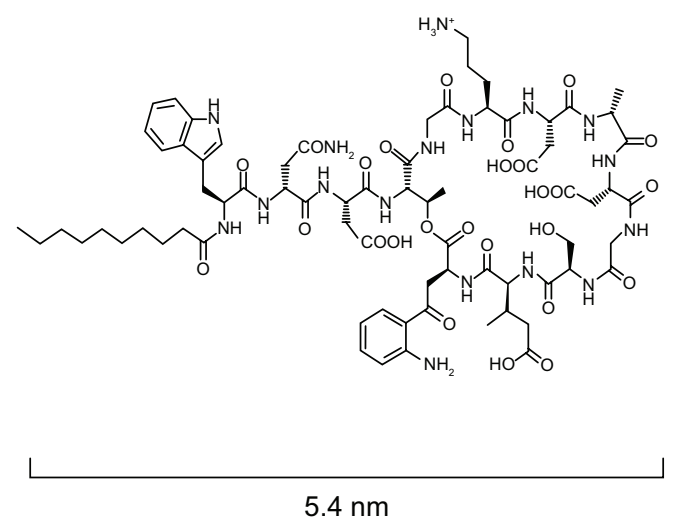

Figure I Molecular structures of the antibiotics used.

Notes: (A) Gentamicin, (B) vancomycin, and (C) daptomycin.

dosages to combat infection, something that has been reported to cause a series of toxic side effects and cell injuries during treatment. ${ }^{16}$

One of the most practical strategies to fight infection would be to apply an implant coating onto medical devices that has the capability to release antimicrobial substances. ${ }^{17-19}$ This would result in local antibiotic administration at the surgical site, which is supposed to be an efficient treatment with low risk for systemic side effects. In addition, reduction of bacterial adhesion to biomedical devices without the use of drugs only by manipulating surface properties is also an attractive method for hindering infections. ${ }^{1,20}$ For example, decreased adhesion of Staphylococcus aureus and Pseudomonas aeruginosa on Ti films has been reported when the nanoroughness was increased. ${ }^{21}$

An effective approach to prevent BAIs would be to combine an antimicrobial release coating with a low bacterial adhesive material, for example, by introducing a specific nanoroughness. ${ }^{22}$ One promising coating in this respect is mesoporous thin films, since they have roughness values in the nano regime combined with the ability to host and deliver antimicrobial drugs. The use of mesoporous coatings on medical devices has also been highlighted in previous studies for improving osseointegration using local administration of osteoporosis-reversing drugs. ${ }^{23}$ Tunable textural properties, high surface area, and pore volume are typical properties of mesoporous materials, which make them suitable candidates for drug-delivery purposes. ${ }^{24-30}$ For example, a sustained release of cephalothin from mesoporous titania-coated implants in vitro has recently been reported. ${ }^{31}$ Moreover, Se Park et al have demonstrated that the sustained release of high dosages of cephalothin and amoxicillin from mesoporous titania surfaces reversed the functions of five different bacterial species. ${ }^{32}$
The aim of the present study was to evaluate how mesoporous titania thin films coated onto titanium substrates affect the formation of bacterial biofilms. The mesoporous films were loaded with antibiotics and the role of film thickness and pore size were evaluated in vitro. More specifically, mesoporous titania thin films, with thicknesses ranging from 250 to $700 \mathrm{~nm}$ and pore diameters of 4,6 , and $7 \mathrm{~nm}$ were formed by the evaporation-induced self-assembly method. The surfaces were loaded with the antimicrobial agents: vancomycin, gentamicin, and daptomycin (molecular structures of the drugs are shown in Figure 1). The mesoporous film effectiveness against $S$. aureus and $P$. aeruginosa biofilm formation, which are two of the most frequent pathogenic species among the detected microbial species responsible for BAI, was evaluated. Chemistry, crystallinity, morphology, existence of long range order, surface energy, and topography of the mesoporous titania surfaces were examined using various characterization methods. The drug uptake and delivery from the mesoporous surfaces were studied using quartz crystal microbalance with dissipation monitoring (QCM-D) and were correlated to the bacterial attachment analysis. The effect of wettability or hydrophilic vs hydrophobic surfaces on bacterial function was also investigated here.

\section{Materials and methods Materials}

All chemicals used in this study were purchased from SigmaAldrich Co. (St Louis, MO, USA). Milli-Q water (18.2 M $\Omega$ ) was used for all the preparations.

\section{Preparation of mesoporous titania substrates}

Cubic mesoporous titania with pore sizes of 4,6 , and $7 \mathrm{~nm}$ were formed using the evaporation-induced self-assembly method. 
The two amphiphiles, Pluronic ${ }^{\circledR}$ P123 (triblock copolymer EO $\mathrm{PO}_{70} \mathrm{EO}_{20}$ ) and cetyltrimethylammonium bromide (CTAB) $\left(\mathrm{CH}_{3}\left(\mathrm{CH}_{2}\right)_{15} \mathrm{~N}(\mathrm{Br})\left(\mathrm{CH}_{3}\right)_{3}\right)$ were used as structure-directing agents. P123 has previously been used for the preparation of mesoporous titania films. ${ }^{33,34}$ Larger pores were provided by the aid of an organic additive, polypropylene glycol (PPG, $\left.M_{n} \sim 4,000\right)$, which was used as a swelling agent.

A titania precursor solution was prepared by adding $2.1 \mathrm{~g}$ titanium (IV) ethoxide (20\%) to $1.6 \mathrm{~g}$ concentrated hydrochloric acid (37\%) under vigorous stirring, forming a homogenous solution. The amphiphile $(0.5 \mathrm{~g})$ was separately dissolved in $8.5 \mathrm{~g}$ ethanol under vigorous stirring followed by mixing with the precursor solution. The final solution was left to stir overnight to achieve a homogenous mixture. To obtain uniform thin films of mesoporous titania, $100 \mu \mathrm{L}$ of the final solution was spin-coated $(7,000 \mathrm{rpm})$ for 1 minute on glass slides $(2 \times 2 \mathrm{~cm})$, titanium discs $(8 \mathrm{~mm}$ diameter and $3 \mathrm{~mm}$ thickness) and Ti-coated QCM-D sensors using a Spin 150 spin coater. The coated substrates underwent aging for 1 day at room temperature to obtain complete self-assembly. When the swelling agent was used, a moderately humid environment $(\mathrm{RH}=54 \%)$ was provided by a saturated $\mathrm{KNO}_{3}$ aqueous solution in a refrigerator $\left(\mathrm{T}=4^{\circ} \mathrm{C} \pm 1^{\circ} \mathrm{C}\right.$ ) during the aging process..$^{35,36}$ Finally, the films were calcinated by heating with a heating ramp of $1^{\circ} \mathrm{C} / \mathrm{min}$ to $350^{\circ} \mathrm{C}$, at which temperature they were left for 4 hours to remove the template and to cross-link the titania. Nonporous titania thin films were formed as control samples using the same procedure, but without the addition of amphiphiles.

\section{Surface modification}

To lower the surface energy of the mesoporous titania thin films, they were treated in a $5 \mathrm{wt} \%$ dichlorodimethylsilane (DCDMS) solution for 1 hour. To ensure a sufficient amount of hydroxyl groups on the titania surface, samples were pre-treated in water baths at $25^{\circ} \mathrm{C}$ for 45 minutes. The glass slides were then placed in a DCDMS solution for 15 minutes and thereafter flushed with chloroform to wash off the unreacted silanol groups from the surface, followed by another 45-minute treatment in DCDMS. ${ }^{37,38}$ The modified films were dried using nitrogen gas.

\section{Immobilization of antibiotics}

Mesoporous titania films were loaded with antibiotics by immersing the substrates in antibiotic solutions for 1 hour. Vancomycin and gentamicin were dissolved in water (1 wt $\%$ ) and daptomycin was dissolved in methanol (1 wt \%). DCDMS-treated mesoporous thin films were used to load daptomycin, and the non-treated surfaces were used for gentamicin and vancomycin.

\section{Material characterization Transmission electron microscopy (TEM)}

TEM was used to visualize the pores in the mesoporous titania films. A JEOL-1200EX II microscope (JEOL, Tokyo, Japan) operating at $120 \mathrm{kV}$ was used. To image the material, mesoporous titania films were scraped off from coated glass slides and dispersed in ethanol. One microliter of the dispersion was placed onto TEM grids (Carbon 300 mesh, Capilor AB, Helsingborg, Sweden) and left to dry before the TEM investigation.

\section{Scanning electron microscopy (SEM)}

A Leo Ultra 55 electron microscope (Carl Zeiss Meditec AG, Oberkochen, Germany) operating at $5 \mathrm{kV}$ was used to analyze the morphological properties of the mesoporous titania thin films. The pore size, pore direction, and film thickness were measured on coated titanium discs and glass microscopy slides. No additional sputtering was needed.

\section{Small angle X-ray scattering (SAXS)}

The structural phase and the existence of long-range order in the mesoporous materials were explored by SAXS measurements. Well-ground powders of mesoporous titania were inserted into SAXS sample holders. The measurements were performed at MAX-lab in Lund, Sweden; beam station 1911. Data were collected with a q-range:

$$
\mathrm{q}=4 \pi \sin \theta / \lambda
$$

of $0.1-3.0 \mathrm{~nm}^{-1}$. The wavelength was $0.91 \AA$, with a beam size of $1.2 \times 1.2 \AA$.

\section{X-ray diffraction (XRD)}

Crystallinity of the $\mathrm{TiO}_{2}$ films was evaluated by XRD. The X-ray diffractometer used was a Bruker D8 advance (Bruker Corporation, Billerica, MA, USA) with a radiation wavelength of $1.5405 \AA$ ( $\mathrm{Cu} K_{\alpha 1}$ radiation). Powders were collected from glass substrates and were ground prior to analysis. Analysis was performed at a $2 \theta$ scanning range of $20^{\circ}-60^{\circ}$, with a step size of $0.05^{\circ}$. The average crystalline sizes were estimated using the Scherrer equation-Equation 2, where D is the mean size of the crystalline domains and $\beta$ is the full width at half maximum of the peak at $2 \theta=25.4^{\circ}$ at the wavelength, $\lambda$, of $1.5405 .{ }^{39}$

$$
\mathrm{D}=\frac{0.94 \lambda}{\beta \cos \theta}
$$




\section{X-ray photoelectron spectroscopy (XPS)}

Chemical analysis of the mesoporous films before and after loading of the antibiotics and with and without the surface modification was performed by XPS. The equipment used was a Quantum 2000 scanning microscope (Physical Electronics, Inc., Chanhassen, MN, USA) with a $100 \mu \mathrm{m}$ point diameter at a $5 \mathrm{~nm}$ analysis depth.

\section{Contact angle}

Static contact-angle measurements were performed on unmodified and DCDMS-treated mesoporous titania surfaces using Milli- $\mathrm{Q}$ water $\left(\mathrm{\gamma}=72.8 \mathrm{mN} \mathrm{m}^{-1}, \mathrm{n}=3\right.$ ). The instrument used was an Attension Theta optical tensiometer (KSV, Helsinki, Finland).

\section{Atomic force microscopy (AFM)}

Semi-contact or intermittent AFM mode was used to measure the surface topography of mesoporous films at two different scan sizes (1 and $0.5 \mu \mathrm{m})$. A conical tip with a length of $200 \mathrm{~nm}$ and a radius of $5 \mathrm{~nm}$ attached to an NT-RTESPA cantilever was used to scan the samples. The AFM used was an NT-MDT model (Moscow, Russia).

\section{Pore volume measurement}

The water-accessible pore volume was measured by $\mathrm{H}_{2} \mathrm{O}$ / $\mathrm{D}_{2} \mathrm{O}$ exchange experiments using QCM-D (Q-sense E4, Biolin Scientific, Stockholm, Sweden). Mesoporous titania thin films were formed on Ti QCM-D sensors according to the procedure described earlier under "Preparation of mesoporous titania substrates". A stable base-line was obtained by adding a flow of Milli-Q water onto the surfaces. Then the flow was exchanged to $\mathrm{D}_{2} \mathrm{O}$ to replace the $\mathrm{H}_{2} \mathrm{O}$ absorbed in the pores. The changes in the frequency $(\Delta f)$ were recorded, which are due to the difference in density and viscosity between $\mathrm{H}_{2} \mathrm{O}$ and $\mathrm{D}_{2} \mathrm{O}$. As a control, the experiments were also carried out on nonporous thin films. In the calculations, the contribution originating from the difference in viscosity between $\mathrm{H}_{2} \mathrm{O}$ and $\mathrm{D}_{2} \mathrm{O}$ was correlated by subtracting the mass increase obtained for the nonporous surface. The obtained $\Delta f$ was used to calculate the mass change utilizing the Sauerbrey equation - Equation 3, where $C$ is the mass sensitivity constant $\left(17.7 \mathrm{ng} \cdot \mathrm{Hz}^{-1} \cdot \mathrm{cm}^{-2}\right)$ and $n$ the overtone number. ${ }^{40}$

$$
\Delta m=-\frac{\Delta f \times C}{n}
$$

Using these data together with film thickness obtained from SEM, the specific pore volume of the mesoporous titania thin films was calculated.

\section{Drug uptake and release}

The uptake and release of antibiotics from the mesoporous titania surfaces were investigated in situ by QCM-D (Q-sense E4). Titanium QCM-D discs (QSX 310, Q-sense) were coated with mesoporous and nonporous titania. For the experiments performed with vancomycin and gentamicin, Milli-Q $\mathrm{H}_{2} \mathrm{O}$ was used as the solvent ( $1 \mathrm{wt} \%$ antibiotic) and the rinsing liquid. In the daptomycin experiments, DCDMStreated sensors were used and methanol was used as solvent (1 wt $\%$ ) and rinsing liquid. All QCM-D experiments were performed under a constant flow of $50 \mathrm{~mL} \mathrm{~min}$. The mass of the adsorbed drugs $\left(\mathrm{ng} \mathrm{cm}^{-2}\right)$ were calculated from the measured frequency changes using the Sauerbrey equation (Equation 3)..$^{40}$

\section{Bacterial assays Bacterial culture}

S. aureus (ATCC 25923 [American Type Culture Collection, Manassas, VA, USA]) and P. aeruginosa (ATCC 35984) were used to assess bacterial growth on the mesoporous titania with varied pore sizes both with and without incorporated antibiotics. One day before the experiments, a sterile $10 \mu \mathrm{L}$ loop was used to withdraw a single isolated colony from cultured agar plates of each bacterium to inoculate a centrifuge tube with $5 \mathrm{~mL}$ of tryptic soy broth. The inoculated cells were cultured in a shaking incubator at $200 \mathrm{rpm}$ for 18 hours at $37^{\circ} \mathrm{C}$ until they reached stationary phase for bacterial growth.

\section{Bacterial growth}

The optical density of the bacterial suspension was adjusted to 0.52 at $620 \mathrm{~nm}$ (estimated to give $10^{9}$ colonies) using a plate reader (Spectramax M3 Multimode Microplate Reader; Molecular Devices LLC, Sunnyvale, CA, USA). Then, each bacterial solution was diluted at a ratio of 1:100 using simulated body fluid (adapted from Oyane et al) ${ }^{41}$ supplemented with $1 \%$ fetal bovine serum (FBS), and $1 \mathrm{~mL}$ of the diluted solution was seeded onto each mesoporous titania sample. Bacteria were then cultured for 1 hour under standard culture conditions $\left(5 \% \mathrm{CO}_{2} / 95 \%\right.$ air at $\left.37^{\circ} \mathrm{C}\right)$ to promote the attachment of the bacteria onto the titania surfaces. After 1 hour of culture, media containing the unattached planktonic bacteria was aspirated. The samples were rinsed once with PBS and fresh media (simulated body fluid $+1 \%$ FBS) were placed onto each sample. Samples were cultured for another 47 hours and at the end of this time period, they were rinsed three times with PBS. Each sample was placed inside a sterile $15 \mathrm{~mL}$ centrifuge tube filled with $2 \mathrm{~mL}$ of PBS. Samples 
were vortexed at 3,000 rpm for 2 minutes to release adherent bacteria into the PBS solution. Afterward, each bacterial solution was diluted twice, 1:10, and then each dilution was plated as five $10 \mu \mathrm{L}$ spots onto sterile tryptic soy broth agar plates. Agar plates were allowed to dry and were then placed inside an incubator at $37^{\circ} \mathrm{C}$ and $5 \% \mathrm{CO}_{2}$ to allow colonies to grow. Once the colonies grew to a point permissive to visual counting ( $\sim 18$ hours), agar plates were taken out of the incubator and individual colonies were counted. From this number, the total number of colonies per milliliter of vortexed solution was calculated and converted to colonyforming units per milliliter.

\section{Statistical analysis}

The numerical data from counting the colony-forming units were presented by the mean value with the standard deviation. All the experiments were conducted three times with three replicates used for each experiment. Statistical significance was considered at $P<0.05$.

\section{Results \\ Material characterization}

SEM micrographs of the coated titanium surfaces showed that the mesoporous titania films were evenly distributed and fully covered the substrate, Figures 2 and S1. A well-defined porous structure was revealed, which had accessible pores facing out from the surfaces. Cross-sections of the coatings were also visualized by SEM (Figure 3), which provided film-thickness estimations. The film thickness was $\sim 200 \mathrm{~nm}$ for the films synthesized with the template P123 and CTAB, while a thicker coating of $\sim 700 \mathrm{~nm}$ was obtained for the films when the swelling agent PPG was added. The mesoporous titania was also investigated using TEM, Figure 4. The average pore diameter and the pore density per surface area were calculated directly from the SEM and TEM micrographs and are presented in Figure 5 and Table 1. From the measured pore sizes, it is clear that the pore diameters correlated well with the size of the template, that is, larger templates resulted in larger pores.

Results from the SAXS measurements are presented in Figure 6. Visible Bragg peaks emerged at different positions, with various intensities demonstrating long-range periodicity in the porous structures. Nonporous samples did not show any peaks in the SAXS results, as expected.

XRD results showed the formation of crystalline anatase $\mathrm{TiO}_{2}$ with no significant difference among the different samples, including the nonporous titania. In Figure 7, a representative diffractogram for the titania films is shown. The peak positions for anatase (mincryst\#191) are also included in the figure. The crystal size was calculated to be $\sim 6 \mathrm{~nm}$ using the Scherrer equation (Equation 2). The pore volume of the titania films was calculated from the QCM-D data obtained from $\mathrm{H}_{2} \mathrm{O} / \mathrm{D}_{2} \mathrm{O}$ exchange experiments using the mass difference between water and heavy water, Table 2.

Results from XPS are shown in Table 3 as the surface chemical composition given in atomic percentage.
A
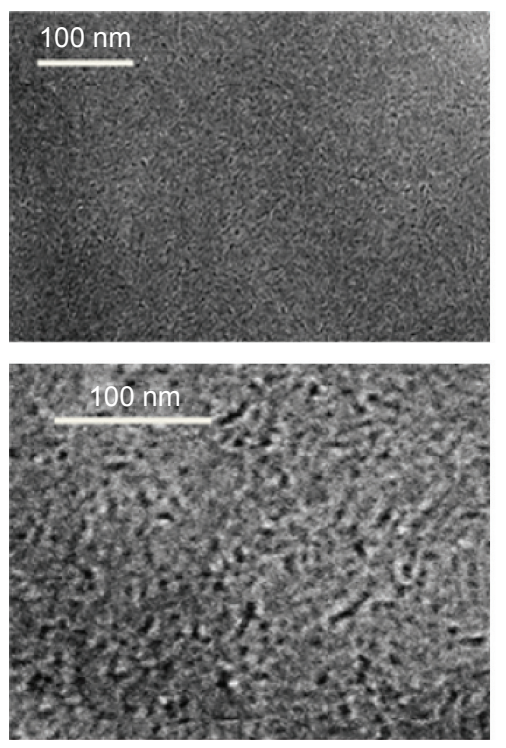

B
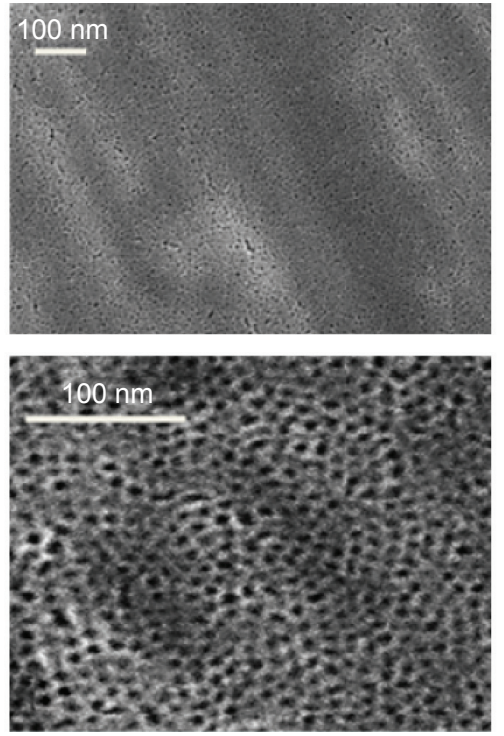

C
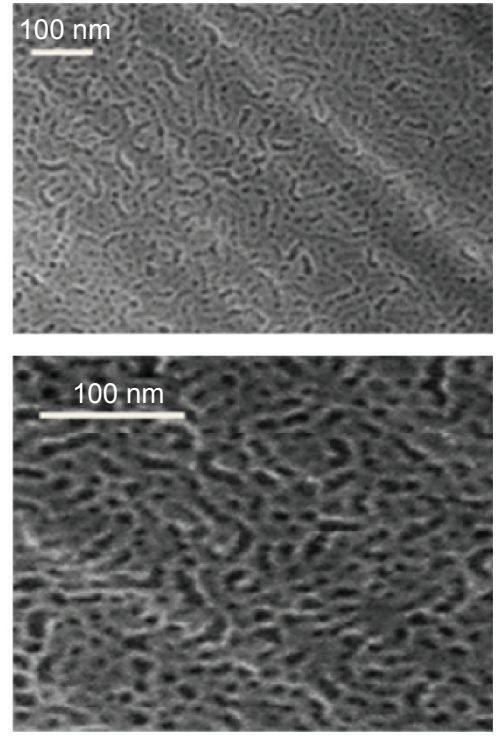

Figure 2 SEM micrographs of mesoporous titania synthesized with different templates presented at two different magnifications.

Notes: (A) CTAB, (B) PI23, and (C) PI23 + PPG (I:I).

Abbreviations: SEM, scanning electron microscopy; CTAB, cetyltrimethylammonium bromide; PI23, Pluronic ${ }^{\circledR}$ PI23; PPG, polypropylene glycol. 

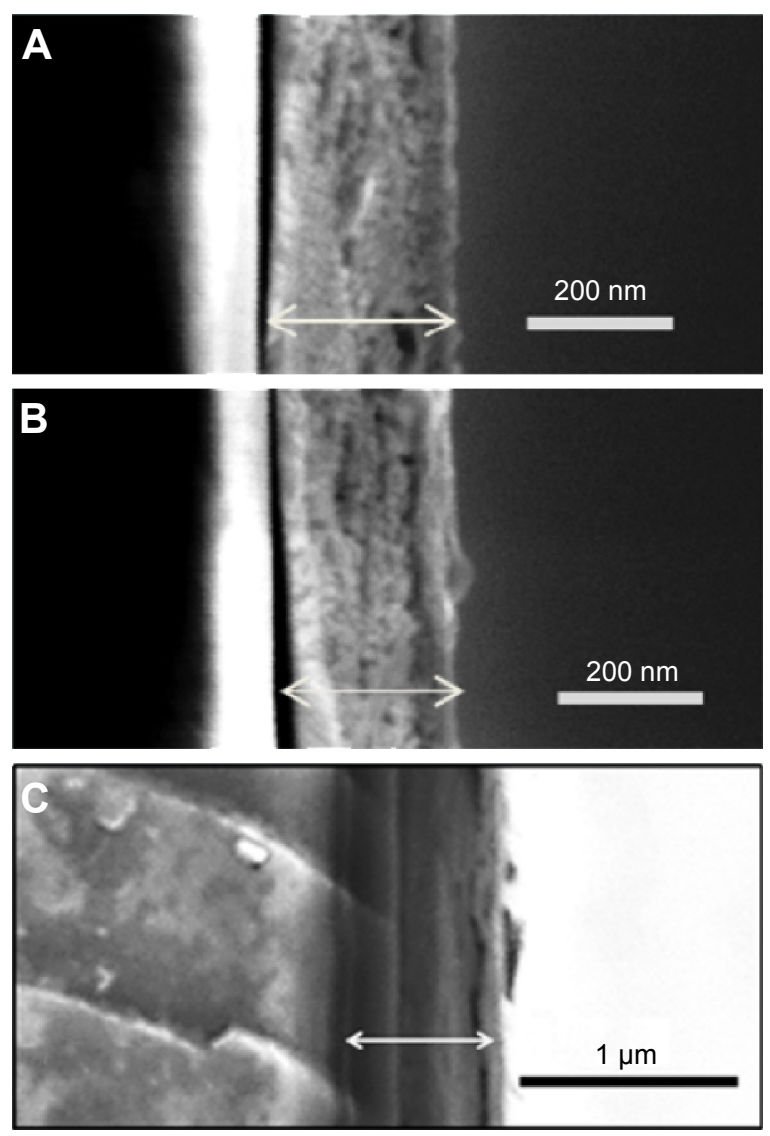

Figure 3 SEM micrographs of the mesoporous titania coating cross-sections on glass slides.

Notes: (A) CTAB, (B) PI23, and (C) PI23 + PPG (I:I)

Abbreviations: SEM, scanning electron microscopy; CTAB, cetyltrimethylammonium bromide; PI23, Pluronic ${ }^{\circledR}$ PI23; PPG, polypropylene glycol.

No significant differences could be observed between the different surfaces.

In Table 4, the obtained average surface roughness values of the films for two different scan sizes are shown. From the results, only small variations in surface roughness values (Ra) could be observed for the different mesoporous films.
The nonporous films were shown to have a smoother surface compared to the porous surfaces. The surface with a $6 \mathrm{~nm}$ pore size was shown to have a slightly rougher surface than the other two pore sizes.

The measured static contact angles were less than $5^{\circ}$ for all unmodified mesoporous titania films. After surface modification with DCDMS, significantly higher contact angles were obtained (Table 5).

\section{Drug uptake and delivery from mesoporous titania surfaces}

The drug uptake and delivery from the mesoporous thin films were monitored using QCM-D. The results clearly demonstrated the loading capacity as well as the release profile for the three antibiotics from the investigated films. In Figure 8 , the amount of drug $\left(\mathrm{ng} / \mathrm{cm}^{2}\right)$ as a function of time is presented. The experimental procedure was as follows: first the drug solution was injected and the drug loading could be determined; second, the surfaces were rinsed with pure solvent and the release was monitored. As can be seen in the figure, the drug-loading capacity increased with increasing pore size. Relatively fast release of the drugs was observed, especially for daptomycin. For gentamicin, no observable difference could be seen between the mesoporous surface having a pore size of $4 \mathrm{~nm}$ and the nonporous, indicating that $4 \mathrm{~nm}$ is too small for gentamicin to penetrate into the porous network. No considerable changes were observed in the dissipation $(\Delta D)$ during the loading and releasing of all drugs during the QCM-D measurements. XPS measurements were performed on the drug-loaded surfaces to confirm the presence of drugs. In Table 6, the identified elements are presented as atomic $\%$. The presence of nitrogen indicates the occurrence of drugs.
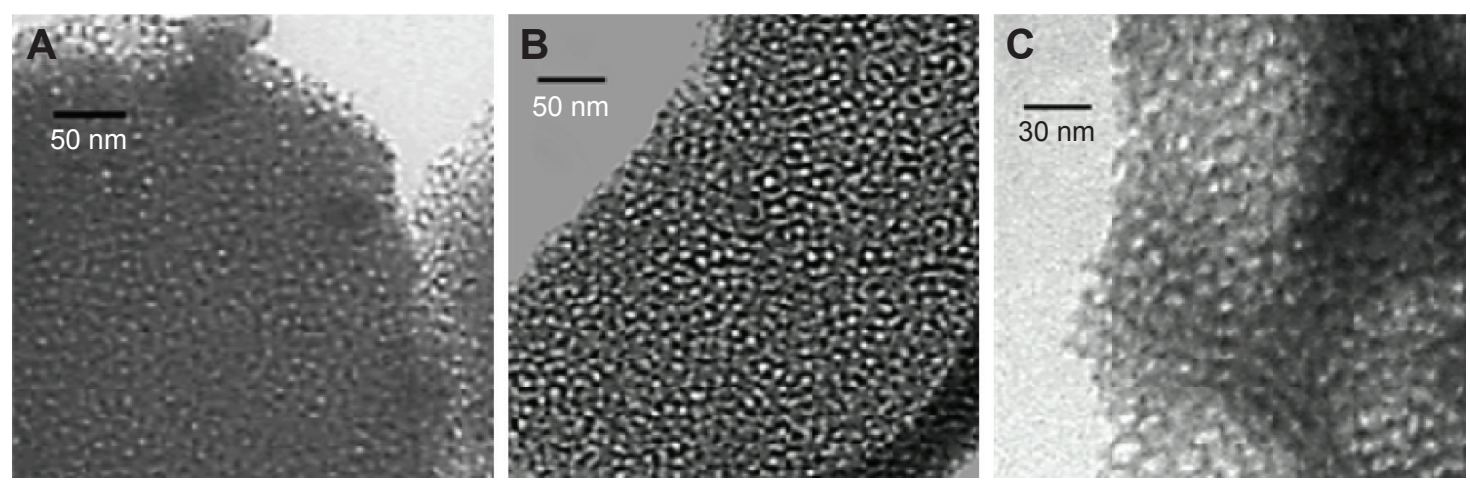

Figure 4 TEM images of mesoporous titania synthesized with the different templates.

Notes: (A) CTAB, (B) PI23, and (C) PI23 + PPG (I:I).

Abbreviations: TEM, transmission electron microscopy; CTAB, cetyltrimethylammonium bromide; PI23, Pluronic ${ }^{\circledR}$ PI23; PPG, polypropylene glycol. 


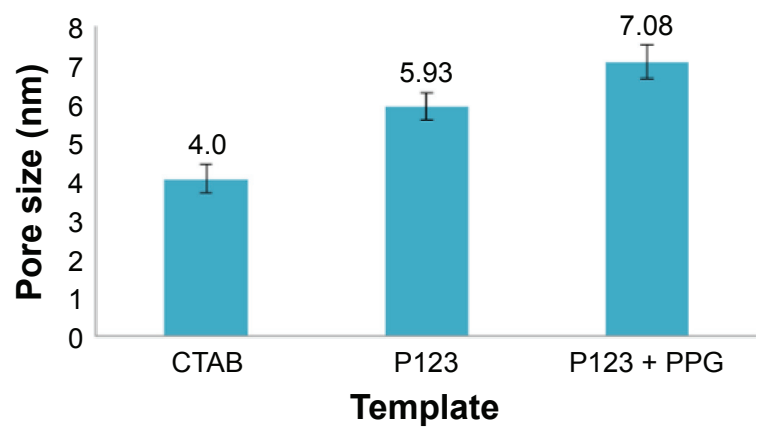

Figure 5 Data from average pore size calculations of mesoporous titania thin films using ten representative SEM and TEM micrographs with the same magnification. Note: Values are mean \pm standard error of the mean.

Abbreviations: SEM, scanning electron microscopy; TEM, transmission electron microscopy; CTAB, cetyltrimethylammonium bromide; PI23, Pluronic ${ }^{\circledR}$ PI23; PPG, polypropylene glycol.

\section{Bacterial adhesion}

The results from bacterial adhesion of $S$. aureus and $P$. aeruginosa are shown in Figure 9. There was a significant decrease in the attachment of colonies for both types of bacteria on the antibacterial loaded surfaces for all antibiotics used. Surfaces with larger pore sizes and loaded with antibiotics gave rise to less colony forming units on the surfaces. Less bacterial attachment was observed on the hydrophobic surfaces and the lowest bacterial adhesion was on hydrophobic substrates loaded with daptomycin (Figure 9).

Furthermore, the presence of the pores alone had a desirable effect on the bacteria without the presence of the drugs, Figure 10.

\section{Discussion}

\section{Material evaluation}

Mesoporous titania thin films with pore diameters of 4, 6 , and $7 \mathrm{~nm}$ were successfully formed as shown by TEM and SEM analysis. According to SEM, uniform films with pores accessible from the surface, which according to SAXS had a long-range order, were formed. Relatively broad peaks appeared in the SAXS data, indicating that the degree of order was relatively low, which is probably a result of the spincoating technique used. When dip coating was used instead of

Table I Estimated average pore sizes measured from SEM and TEM images

\begin{tabular}{lll}
\hline Template & $\begin{array}{l}\text { Average pore } \\
\text { diameter }\end{array}$ & $\begin{array}{l}\text { Pore surface } \\
\text { coverage }( \pm \mathbf{5} \%)\end{array}$ \\
\hline CTAB & 4 & 18 \\
PI23 & 6 & 25 \\
PI23 + PPG (I:I) & 7 & 42 \\
\hline
\end{tabular}

Abbreviations: SEM, scanning electron microscopy; TEM, transmission electron microscopy; CTAB, cetyltrimethylammonium bromide; PI23, Pluronic ${ }^{\circledR}$ PI23; PPG, polypropylene glycol.

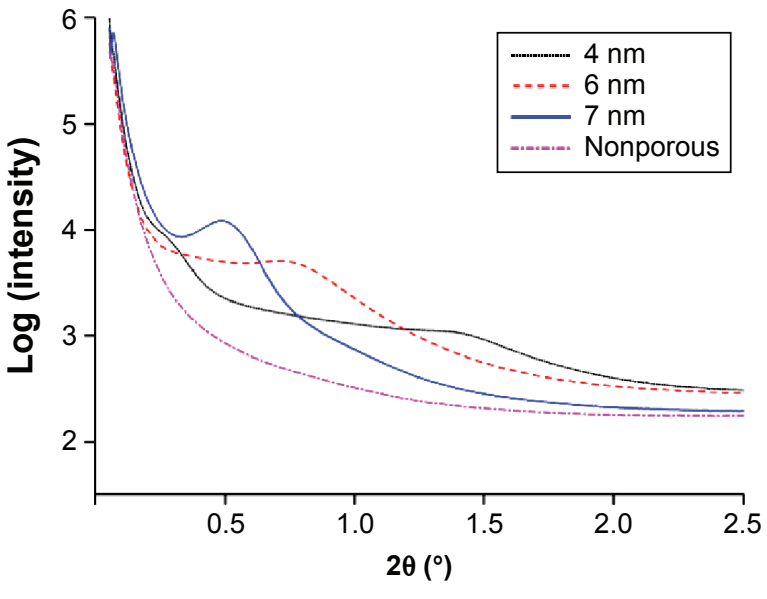

Figure 6 Synchroton small angle X-ray scattering diffractograms of mesoporous titania.

spin coating, a higher degree of ordering was often observed; however, less homogeneous films were then formed. . $^{42,43}$ The ordering of the material was not considered to be of high significance in this particular application; however, the fact that the pores are present on the outer surface is a prerequisite for these coatings to function as drug-delivery matrices. When PPG was used as a swelling agent, thicker coatings $(700 \mathrm{~nm}$ instead of $200 \mathrm{~nm}$ ) were obtained, which is probably due to the viscosity increase for the PPG-containing solution used in the spin-coating process. The crystalline structure of all the formed films (according to XRD) was anatase $\mathrm{TiO}_{2}$. However, a large degree of amorphous titania is also to be expected. The Bragg peaks were broad, indicating that the crystal size was small $(6 \mathrm{~nm})$, which correlates well with previous studies. ${ }^{43}$ XPS showed that the surface chemistry was similar on all the formed films, including the nonporous films, and consisted of carbon, oxygen, and titanium. The surface roughness values, as obtained from AFM, showed that the films were smooth,

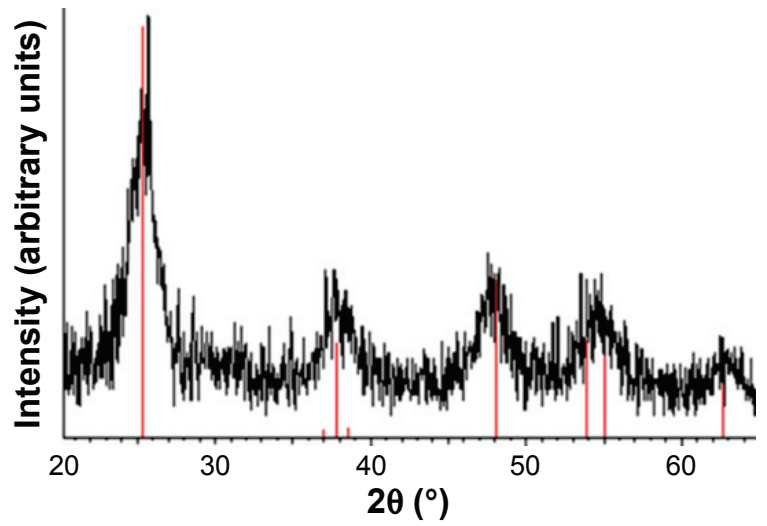

Figure 7 A representative $X$-ray diffractogram obtained from mesoporous titania powders.

Note: The anatase phase could be identified according to \#I9I (MINCRYST). 
Table 2 The water-accessible pore volume of the mesoporous titania thin films obtained from QCM-D measurements

\begin{tabular}{lll}
\hline Template & \multicolumn{2}{l}{ Pore volume percentage (\%) } \\
\cline { 2 - 3 } & Pure titania films & DCDMS treated films \\
\hline PI23 + PPG (I:I) & 75 & $7 I$ \\
PI23 & 57 & 55 \\
CTAB & 55 & 49 \\
\hline
\end{tabular}

Note: Results for non-treated and DCDMS treated mesoporous titania thin films are shown.

Abbreviations: QCM-D, quartz crystal microbalance with dissipation monitoring; DCDMS, dichlorodimethylsilane; CTAB, cetyltrimethylammonium bromide; PI23, Pluronic ${ }^{\circledast}$ PI23; PPG, polypropylene glycol.

with no major changes in the roughness for the different pore sizes. This shows that the cantilever tip was too broad to reach inside the pores and hence scanned above the porous structure. The use of narrower cantilevers, less than $5 \mathrm{~nm}$ in width, was tested; however, these also failed to provide measurements of the actual pores. The only considerable difference in surface roughness could be observed between the porous and nonporous surfaces; however, all were still considered to be smooth on a micrometer length scale. The surface energy of the films was examined using static contact-angle measurements, which showed that all surfaces were hydrophilic or even super hydrophilic. After surface modification with DCDMS, the surface energy drastically decreased, forming hydrophobic (contact angles above $90^{\circ}$ ) or close to hydrophobic surfaces. This provides clear evidence that the polar hydroxyl groups had been substituted with the non-polar methylene groups of the DCDMS.

The water-accessible pore volume was examined using QCM-D. As expected, the volume increased with increasing pore size and increased film thickness. The fact that the volume increased with film thickness, is a strong indication that the pores are accessible throughout the whole film, and thus makes it possible to tune the available drug-loading capacity by altering films thickness, which is achievable through changes in the spin-coating speed as well as other parameters. The DCDMS modified films showed a small decrease in pore volume compared to their non-treated counterparts. This shows that, although the surfaces were hydrophobic, water could still penetrate into the small pores.

Table 3 The atomic percentage of the chemical composition on the mesoporous titania thin films

\begin{tabular}{llll}
\hline Template & CIs & Ols & Ti2p \\
\hline PI23 + PPG & 26.85 & 53.88 & 19.03 \\
CTAB & 24.79 & 55.32 & 19.16 \\
PI23 & 20.7 & 57.43 & 21.88 \\
\hline
\end{tabular}

Abbreviations: $C T A B$, cetyltrimethylammonium bromide; $\mathrm{PI} 23$, Pluronic ${ }^{\circledR} \mathrm{PI} 23$; PPG, poly propylene glycol.
Table 4 Average roughness $(\mathrm{Ra})$ obtained by atomic force microscopy (AFM) from mesoporous titania surfaces in two different scan sizes

\begin{tabular}{lll}
\hline Average roughness (Ra) by AFM $(\mathbf{n m})$ & \\
\hline Pore size $(\mathbf{n m})$ & $\mathbf{0 . 5} \times \mathbf{0 . 5} \boldsymbol{\mu \mathbf { m }}$ & $\mathbf{I} \times \mathbf{I} \boldsymbol{\mu \mathbf { m }}$ \\
\hline 7 & 10.35 & 14.80 \\
6 & 19.74 & 24.74 \\
4 & 10.17 & 12.87 \\
Nonporous & 0.96 & 1.85 \\
\hline
\end{tabular}

All the different material characterizations performed here clearly demonstrated that the chemistry and physical properties of the different porous materials were similar or in some cases even identical, which provides a possibility to explore the effect of the pore size alone on drug loading and release as well as antibacterial properties.

\section{Antibiotic loading and delivery from mesoporous titania thin films}

A key parameter in creating a suitable drug delivery coating is the loading capacity. According to the obtained results, the loading behavior of each drug corresponded well with the volume of the pores as measured by $\mathrm{H}_{2} \mathrm{O}$ adsorption. The larger pore sizes had the ability to host larger amounts of drugs per surface area of the coating, which was demonstrated by the QCM-D results when the mesoporous thin films were loaded with, for example, vancomycin (Figure 8). The size of vancomycin is $\sim 3 \mathrm{~nm}$, allowing it to be successfully loaded into all the explored pore-sizes. ${ }^{44}$ For gentamicin, a successful loading was observed for the mesoporous titania with pore sizes of 6 and $7 \mathrm{~nm}$ followed by a sustained-release pattern, Figure 8 . For the $4 \mathrm{~nm}$ pore size, however, no difference compared with the nonporous surfaces could be observed, indicating that gentamicin could not access the $4 \mathrm{~nm}$ pores. This is explained by the fact that gentamicin is believed to have an affinity to titania that may create blockage of the pore walls upon adsorption. When comparing the release data of vancomycin and gentamicin, a difference in the release kinetics could be observed. Vancomycin had a faster release, indicating that the drug had only a low adherence to

Table 5 Contact-angle results before and after DCDMS modification

\begin{tabular}{lll}
\hline Surface & $\begin{array}{l}\text { Contact angle }\left({ }^{\circ}\right) \\
\text { on pure titania }\end{array}$ & $\begin{array}{l}\text { Contact angle }\left({ }^{\circ}\right) \text { after } \\
\text { DCDMS treated }\end{array}$ \\
\hline $4 \mathrm{~nm}$ & $<5$ & 85 \\
$6 \mathrm{~nm}$ & $<5$ & 80 \\
$7 \mathrm{~nm}$ & $<5$ & 110 \\
Nonporous & 7 & 100 \\
\hline
\end{tabular}

Abbreviation: DCDMS, dichlorodimethylsilane. 


\section{A}

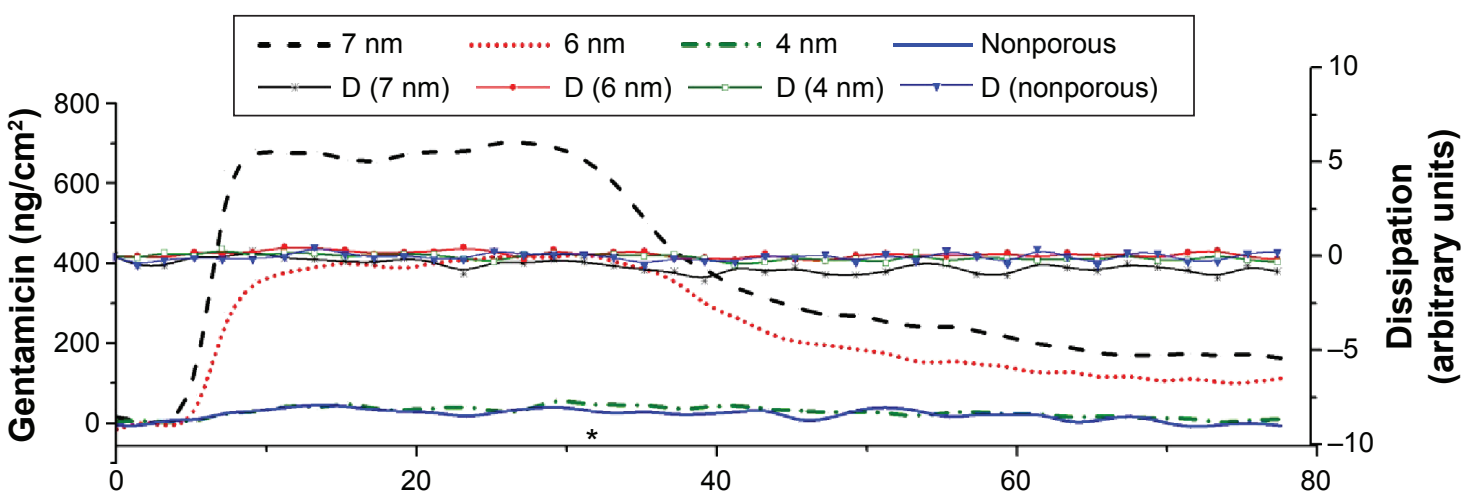

B
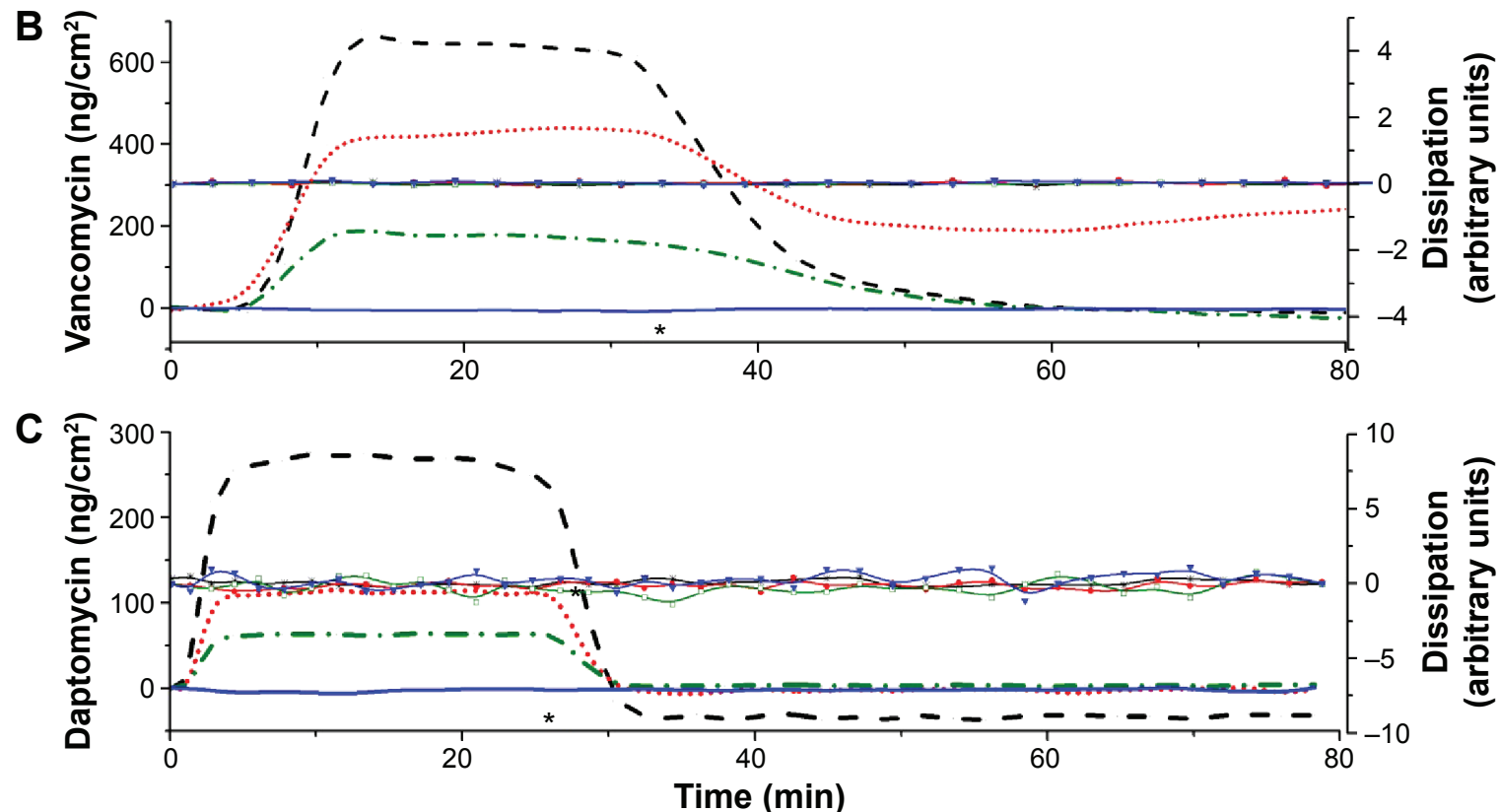

Figure 8 QCM-D results obtained from loading and release of the three different antibiotics.

Notes: (A) Gentamicin, (B) vancomycin, and (C) daptomycin on mesoporous titania with variable pore sizes (for daptomycin DCDMS-modified surfaces were used). *Indicates start of rinsing with solvent following the release.

Abbreviations: QCM-D, quartz crystal microbalance with dissipation monitoring; DCDMS, dichlorodimethylsilane; min, minutes.

the pore walls and, instead, was highly dissolved in the water within the pores; hence the measured frequency difference between water and the vancomycin solution was due to the difference in density between the two. The third antibiotic used was daptomycin, which is a larger molecule compared to the other two antibiotics. It also has a low water solubility; thus, DCDMS-modified surfaces were used for this drug. According to Figure 8, a trend in the loading was observed, which followed the expected tendency with increasing drug amount as the pore size increased. Upon rinsing with methanol, a relatively fast release was observed. Apart from key parameters, including pore size and the available surface area,

Table 6 XPS data showing the chemical composition (atomic \%) of mesoporous titania with a pore size of 6 nm and nonporous titania thin films after loading with vancomycin, daptomycin, and gentamicin antibiotics

\begin{tabular}{lllllll}
\hline Samples & Antibiotic & Cls & NIs & Ols & Ti2p & Si2p \\
\hline Mesoporous titania & Vancomycin & 20.55 & 5.87 & 55.03 & 18.55 & 23.85 \\
Nonporous titania & & 16.03 & 0.30 & 59.82 & 16.78 & 1.50 \\
Mesoporous titania & Daptomycin & 20.89 & 5.30 & 55.54 & 5.22 & 24.60 \\
Nonporous titania & & 15.89 & 0.29 & 48.89 & 17.89 & 24.99 \\
Mesoporous titania & Gentamicin & 26.94 & 6.29 & 59.66 & & \\
Nonporous titania & & 15.03 & 0.33 & & &
\end{tabular}

Note: The data are presented as atomic \%.

Abbreviation: XPS, X-ray photoelectron spectroscopy. 

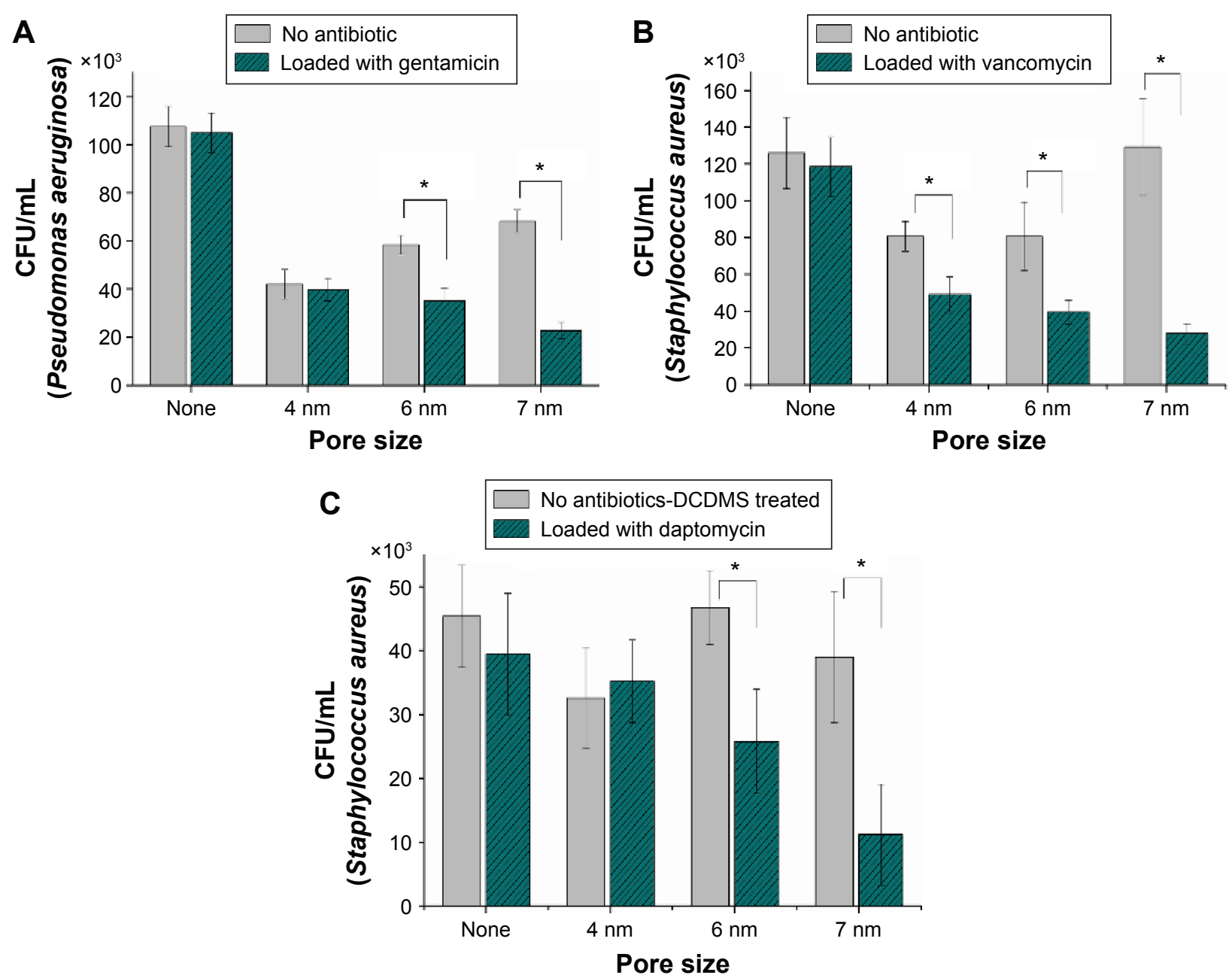

Figure 9 Data from counting the colony-forming units (CFU) grown on mesoporous titania with and without antibiotics.

Notes: (A) Gentamicin, (B) vancomycin, and $(\mathbf{C})$ daptomycin. Values are mean \pm standard error of the mean, $N=3, * P<0.05$ compared to all mesoporous titania surfaces of the same pore size.

Abbreviation: DCDMS, dichlorodimethylsilane.

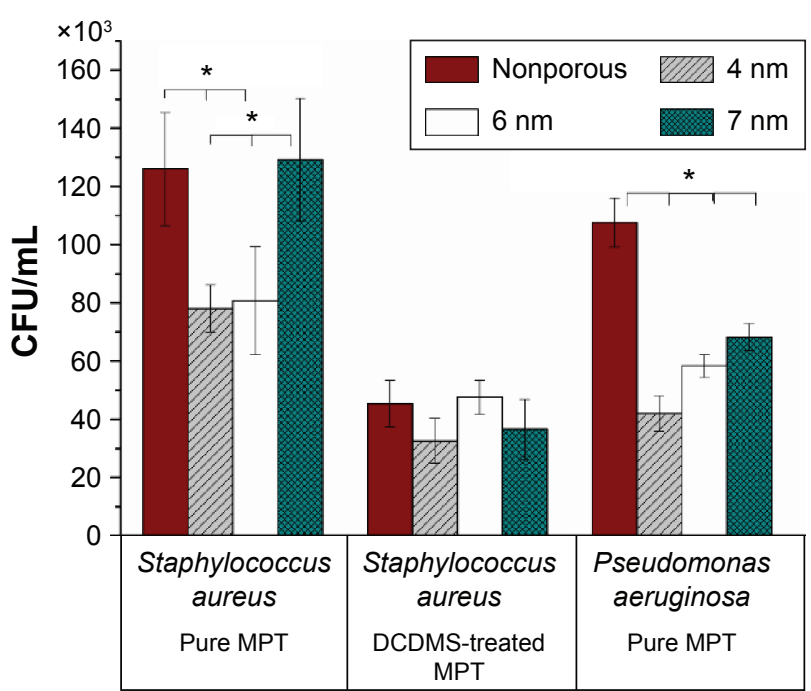

Figure 10 Data from counting the colony-forming units (CFU) grown on modified and unmodified mesoporous titania without the presence of antibiotics.

Notes: Values are mean \pm standard error of the mean, $N=3, * P<0.05$ compared to mesoporous titania surfaces for each bacterial strain.

Abbreviations: DCDMS, dichlorodimethylsilane; MPT, mesoporous titania. the characteristics of the drugs (such as size and polarity) clearly played an important role. The dissipation $(\Delta D)$ did not change noticeably during the loading and releasing of drugs as a function of time. This observation indicates that there were no viscoelastic films formed due to adsorption of drugs onto the mesoporous thin films.

It should be noted that all drug-release studies were monitored upon constant rinsing with the solvent, water or methanol, at a rate of $50 \mathrm{~mL} \mathrm{~min}{ }^{-1}$. Compared to an in vivo situation, for example in bone tissue, this is a much faster exchange of surrounding media resulting in a much faster release and, consequently, the present release profiles cannot be directly transferred to the clinical situation and should be considered highly accelerated.

\section{Bacterial cell culture}

Early clinical failure of implants often arises from improper tissue integration. This failure is often caused by the development 
of a bacterial biofilm and chronic infection at the site of surgery. Previous studies have emphasized the possible fabrication of antimicrobial surfaces using nanotechnology; although applying nanotechnology to create roughness values in the nanometer regime on the implant surfaces needs to be further addressed. ${ }^{45-47}$ Results from this present study showed that applying a mesoporous thin coating on surfaces, apart from their function as an antibiotic-delivery system, can reduce the adhesion of bacteria only by the presence of nano-sized pores. S. aureus showed a reduced bacterial attachment on surfaces with smaller pore sizes, 4 and $6 \mathrm{~nm}$, and a trend in the reduction of $P$. aeruginosa was observed with reducing pore size. Looking at the measured material characteristics (including surface energy, surface roughness, and surface chemistry), in an effort to find a reasonable explanation for the observed bacterial behavior, no obvious connections could be found. For both bacteria, the smallest pore size had the lowest bacterial adhesion; however, this material did not exhibit any unique material characteristics, except for the change in pore size. A possible explanation for the observed trend is that protein adsorption and bioactivity are affected by the changes in the nanotopography caused by changing the pore width. Moreover, the distribution of the pores (pore surface coverage shown in Table 1) and consequently the pore wall thickness differs due to the changes in pore width. It is known that the $3 \mathrm{D}$ conformation of proteins, which is present in the bacterial growth media, can be altered by changes in the nanotopography, which can potentially have an effect on bacterial adhesion. ${ }^{48}$ Similar behavior of bacterial attachment responses by changing the nanotopography have previously been observed regarding the use of carbon nanotubes and nanostructured gold surfaces. ${ }^{23,49}$ Moreover, the formed mesoporous materials have a long-range order, something that has been previously shown to affect cell responses. ${ }^{50}$ This implies that apart from the traditional means of characterizing biomaterials, both when it comes to tissue integration properties as well as antimicrobial behaviors, studies should be performed with respect to ordering and size of nanostructured domains.

According to the results obtained from counting colony forming units, the best surfaces to reduce bacterial attachments without the presence of antibiotics was the hydrophobic mesoporous titania with $4 \mathrm{~nm}$ pore sizes showing that the bacterial attachment was lower when the surface energy of the substrate decreased. It is not clear whether it is the surface free energy of the substrates that directly controls the bacterial adhesion or the fact that adsorption of the FBS, present in the culture medium, is affected, thus reducing bacterial adhesion. Similar behavior has been observed with
BSA, which decreases bacterial attachment on hydrophobic polystyrene substrates. ${ }^{51}$ Moreover, it has previously been shown that the presence of FBS in the culture medium has a negative effect on the adhesion of cells on hydrophobic surfaces. ${ }^{52}$

When the mesoporous titania was loaded with antibiotics, a predictable pattern was observed. According to Table 2, the pore volume increased with increasing pore size and the results from QCM-D measurements clearly showed that the amount of antibiotics followed the same trend. These observations correlated well with the bacterial adhesion results, which showed clear differences in the adhesion of bacteria when different antibiotic loadings were used. Regardless of the type of antibiotic and the bacteria, an expected decreased attachment was observed with increased amounts of antibiotics. These observations confirm that the mesoporous titania substrates can act as an efficient drug release coating on implants to fight bacterial adhesion and potential infection caused by the formation of biofilms. The amount of antibiotic loaded in the coating can be regulated by varying the pore size and the thickness of the mesoporous titania film.

As mentioned earlier, the use of mesoporous titania thin films as implant coatings has previously been shown to have promising effects on the osseointegration of titanium implants. ${ }^{53}$ The integration of such implants was further improved using osteoporosis drugs, alendronate and raloxifene, which were administrated locally from the mesoporous film. ${ }^{23}$ Both the mechanical stability and the amount of formed bone were shown to increase. The results from this present study also showed an additional favorable property of the mesoporous films, that is, that they also decreased bacterial adhesion, both with and without the use of antibiotics. This is a highly desirable property, which clearly demonstrates that the use of nanostructural surface design is important when the "race for the surface" is of the essence; here providing a means for tissue growth and a reduced risk for BAIs. The use of drugs in implantology, especially when the implant functions as a drug-delivery device, is still in its infancy, something highly driven by the regulatory legislation; however, as demonstrated by us and others, could be highly beneficial. The use of local drug administration is a way to decrease the amount of drugs used and to obtain site-specific efficient treatment. The occurrence of a possible negative side effect might also be hindered, although this needs to be further investigated.

\section{Conclusion}

Mesoporous titania thin films with well-defined pore sizes of 4,6 , and $7 \mathrm{~nm}$ were successfully obtained. Both the films 
with and without antimicrobial agents, including gentamicin, vancomycin, and daptomycin were evaluated with respect to bacterial attachment. The mesoporous titania films were shown to have a desired property in reducing bacterial attachment and a declining trend was observed as a function of pore size. The antibiotic loading was shown to improve antimicrobial behavior for all surfaces and the effect correlated well with the amount of the released drug. Moreover, the present hydrophobic modification of the mesoporous titania films decreased the adhesion of bacteria.

\section{Acknowledgments}

The Wallenberg Foundation is acknowledged for financial support through their Wallenberg Academy Fellow Program (MA). Northeastern University is also acknowledged for financial support. Katherine Y Santizo is acknowledged for the AFM measurements.

\section{Disclosure}

The authors report no conflicts of interest in this work.

\section{References}

1. Campoccia D, Montanaro L, Arciola CR. The significance of infection related to orthopedic devices and issues of antibiotic resistance. Biomaterials. 2006;27(11):2331-2339.

2. Seil JT, Webster TJ. Reduced Staphylococcus aureus proliferation and biofilm formation on zinc oxide nanoparticle PVC composite surfaces. Acta Biomater. 2011;7(6):2579-2584.

3. Franz S, Rammelt S, Scharnweber D, Simon JC. Immune responses to implants - a review of the implications for the design of immunomodulatory biomaterials. Biomaterials. 2011;32(28):6692-6709.

4. Roy M, Bandyopadhyay A, Bose S. In vitro antimicrobial and biological properties of laser assisted tricalcium phosphate coating. Mater Sci Eng C Mater Biol Appl. 2009;29(6):1965-1968.

5. Sanzén L, Linder L. Infection adjacent to titanium and bone cement implants: an experimental study in rabbits. Biomaterials. 1995;16(16): $1273-1277$.

6. Kazemzadeh-Narbat M, Kindrachuk J, Duan K, Jenssen H, Hancock RE, Wang R. Antimicrobial peptides on calcium phosphate-coated titanium for the prevention of implant-associated infections. Biomaterials. 2010;31(36):9519-9526.

7. Chen W, Liu Y, Courtney HS, et al. In vitro anti-bacterial and biological properties of magnetron co-sputtered silver-containing hydroxyapatite coating. Biomaterials. 2006;27(32):5512-5517.

8. Arciola CR, Campoccia D, Speziale P, Montanaro L, Costerton JW. Biofilm formation in Staphylococcus implant infections. A review of molecular mechanisms and implications for biofilm-resistant materials. Biomaterials. 2012;33(26):5967-5982.

9. Campoccia D, Montanaro L, Arciola CR. A review of the biomaterials technologies for infection-resistant surfaces. Biomaterials. 2013;34(34):8533-8554.

10. Darouiche RO. Treatment of infections associated with surgical implants. N Engl J Med. 2004;350(14):1422-1429.

11. Montanaro L, Speziale P, Campoccia D, et al. Scenery of Staphylococcus implant infections in orthopedics. Future Microbiol. 2011;6(11): 1329-1349.

12. Ercan B, Taylor E, Alpaslan E, Webster TJ. Diameter of titanium nanotubes influences anti-bacterial efficacy. Nanotechnology. 2011;22(29): 295102.
13. Tunney MM, Ramage G, Patrick S, Nixon JR, Murphy PG, Gorman SP. Antimicrobial susceptibility of bacteria isolated from orthopedic implants following revision hip surgery. Antimicrob Agents Chemother. 1998;42(11):3002-3005.

14. Went $\mathrm{P}$, Krismer M, Frischhut B. Recurrence of infection after revision of infected hip arthroplasties. J Bone Joint Surg Br. 1995;77(2): 307-309.

15. Lange J, Troelsen A, Thomsen RW, Søballe K. Chronic infections in hip arthroplasties: comparing risk of reinfection following one-stage and two-stage revision: a systematic review and meta-analysis. Clin Epidemiol. 2012;4:57-73.

16. Popat KC, Eltgroth M, Latempa TJ, Grimes CA, Desai TA. Decreased Staphylococcus epidermis adhesion and increased osteoblast functionality on antibiotic-loaded titania nanotubes. Biomaterials. 2007;28(32): 4880-4888.

17. Matl FD, Obermeier A, Repmann S, Friess W, Stemberger A, Kuehn KD. New anti-infective coatings of medical implants. Antimicrob Agents Chemother. 2008;52(6):1957-1963.

18. Ramstedt M, Ekstrand-Hammarström B, Shchukarev AV, et al. Bacterial and mammalian cell response to poly(3-sulfopropyl methacrylate) brushes loaded with silver halide salts. Biomaterials. 2009;30(8): 1524-1531.

19. Sambhy V, MacBride MM, Peterson BR, Sen A. Silver bromide nanoparticle/polymer composites: dual action tunable antimicrobial materials. J Am Chem Soc. 2006;128(30):9798-9808.

20. Puckett SD, Taylor E, Raimondo T, Webster TJ. The relationship between the nanostructure of titanium surfaces and bacterial attachment. Biomaterials. 2010;31(4):706-713.

21. Ivanova EP, Truong VK, Wang JY, et al. Impact of nanoscale roughness of titanium thin film surfaces on bacterial retention. Langmuir. 2010;26(3):1973-1982.

22. Williams DL, Sinclair KD, Jeyapalina S, Bloebaum RD. Characterization of a novel active release coating to prevent biofilm implantrelated infections. J Biomed Mater Res B Appl Biomater. 2013;101(6): 1078-1089.

23. Harmankaya N, Karlsson J, Palmquist A, et al. Raloxifene and alendronate containing thin mesoporous titanium oxide films improve implant fixation to bone. Acta Biomater. 2013;9(6):7064-7073.

24. Zhou L, Zheng X, Gu Z, et al. Mesoporous NaYbF4@NaGdF4 coreshell up-conversion nanoparticles for targeted drug delivery and multimodal imaging. Biomaterials. 2014;35(26):7666-7678.

25. Vallet-Regí M, Balas F, Arcos D. Mesoporous materials for drug delivery. Angew Chem Int Ed Engl. 2007;46(40):7548-7558.

26. Wu KC, Yamauchi Y. Controlling physical features of mesoporous silica nanoparticles (MSNs) for emerging applications. J Mater Chem. 2012;22:1251-1256.

27. Vivero-Escoto JL, Chiang YD, Wu KC, Yamauchi Y. Recent progress in mesoporous titania materials: adjusting morphology for innovative applications. Sci Technol Adv Mater. 2012;13:013003.

28. Yamauchi Y. Field-induced alignment controls of one-dimensional mesochannels in mesoporous materials. Journal of Ceramic Society of Japan. 2013;121:831-840.

29. Chen S, Zhu Y, Li W, et al. Synthesis, features, and applications of mesoporous titania with $\mathrm{TiO}_{2}$ (B). Chinese Journal of Catalysis. 2010;31(6): 605-614.

30. Luo Z, Hu Y, Cai K, et al. Intracellular redox-activated anticancer drug delivery by functionalized hollow mesoporous silica nanoreservoirs with tumor specificity. Biomaterials. 2014;35(27):7951-7962.

31. Xia W, Grandfield K, Hoess A, Ballo A, Cai Y, Engqvist H. Mesoporous titanium dioxide coating for metallic implants. J Biomed Mater Res B Appl Biomater. 2012;100(1):82-93.

32. Park SW, Lee D, Choi YS, et al. Mesoporous TiO2 implants for loading high dosage of antibacterial agent. Appl Surf Sci. 2014;303: 140-146.

33. Weng W, Higuchi T, Suzuki M, et al. A high-speed passive-matrix electrochromic display using a mesoporous $\mathrm{TiO} 2$ electrode with vertical porosity. Angew Chem Int Ed Engl. 2010;49(23):3956-3959. 
34. Oveisi H, Rahighi S, Jiang X, et al. Unusual antimicrobial property of mesoporous titania films: Drastic improvement by controlling surface area and crystallinity. Chem Asian J. 2010;5(9):1978-1983.

35. Wu QL, Rankin SE. Tuning the mesopore size of titania thin films using a polymeric swelling agent. J Phys Chem C. 2011;115(24): 11925-11933.

36. Wu QL, Subramanian N, Rankin SE. Hierarchically porous titania thin film prepared by controlled phase separation and surfactant templating. Langmuir. 2011;27(15):9557-9566.

37. Lessel M, Bäumchen $\mathrm{O}$, Klos M, et al. Self-assembled silane monolayers: A step-by-step high speed recipe for high-quality, low energy surfaces. Condensed Matter Materials Science. 2012:29-31.

38. Almanza-Workman AM, Raghavan S, Petrovic S, et al. Characterization of highly hydrophobic coatings deposited onto pre-oxidized silicon from water dispersible organosilanes. Thin Solid Films. 2003;423(1): 77-87.

39. Reddy KM, Manorama SV, Reddy AR. Bandgap studies on anatase titanium dioxide nanoparticles. Mater Chem Phys. 2002;78:239-245.

40. Dixon MC. Quartz crystal microbalance with dissipation monitoring: enabling real-time characterization of biological materials and their interactions. J Biomol Tech. 2008;19(3):151-158.

41. Oyane A, Kim HM, Furuya T, Kokubo T, Miyazaki T, Nakamura T. Preparation and assessment of revised simulated body fluids. J Biomed Mater Res A. 2003;65(2):188-195.

42. Alberius PC, Frindell KL, Hayward RC, Kramer EJ, Stucky GD, Chmelka BF. General predictive syntheses of cubic, hexagonal, and lamellar silica and titania mesostructured thin films. Chem Mater. 2002;14(8): 3284-3294.

43. Andersson M, Birkedal H, Franklin NR, et al. Ag/AgCl-loaded ordered mesoporous anatase for photocatalysis. Chem Mater. 2005;17(6): 1409-1415.
44. Cauda V, Onida B, Platschek B, Mühlstein L, Bein T. Large antibiotic molecule diffusion in confined mesoporous silica with controlled morphology. J Mater Chem. 2008;18:5888-5899.

45. Rizzello L, Cingolani R, Pompa PP. Nanotechnology tools for antibacterial materials. Nanomedicine (Lond). 2013;8(5):807-821.

46. Sengstock C, Lopian M, Motemani Y, et al. Structure-related antibacterial activity of a titanium nanostructured surface fabricated by glancing angle sputter deposition. Nanotechnology. 2014;25(19):195101.

47. Taylor E, Webster TJ. Reducing infections through nanotechnology and nanoparticles. Int J Nanomedicine. 2011;6:1463-1473.

48. Hulander M, Lundgren A, Faxälv L, et al. Gradients in surface nanotopography used to study platelet adhesion and activation. Colloids Surf B Biointerfaces. 2013;110:261-269.

49. Svensson S, Forsberg M, Hulander M, et al. Role of nanostructured gold surfaces on monocyte activation and Staphylococcus epidermidis biofilm formation. Int J Nanomedicine. 2014;9:775-794.

50. Dalby MJ, Gadegaard N, Tare R, et al. The control of human mesenchymal cell differentiation using nanoscale symmetry and disorder. Nat Mater. 2007;6(12):997-1003.

51. Fletcher M. The effects of proteins on bacterial attachment to polystyrene. Journal of General Microbiology. 1975;94:400-404.

52. Carré A, Lacarrière V. Cell adhesion to polystyrene substrates: relevance of interfacial free energy. In: Mittal KL, editor. Contact angle, wettability and adhesion. Boston: Leiden; 2008:253-267.

53. Karlsson J, Jimbo R, Fathali HM, et al. In vivo biomechanical stability of osseointegrating mesoporous $\mathrm{TiO}(2)$ implants. Acta Biomater. 2012;8(12):4438-4446. 


\section{Supplementary material}
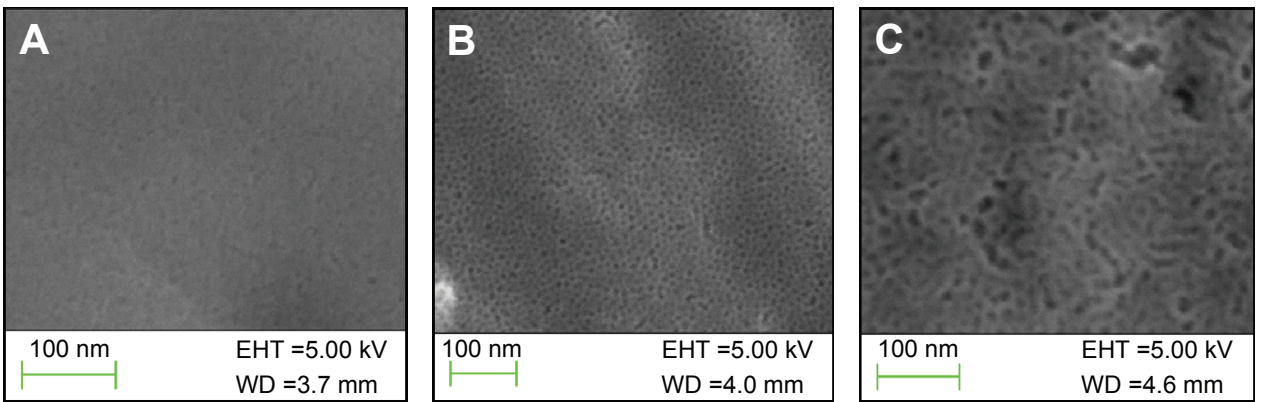

Figure SI SEM micrographs of mesoporous titania coated onto glass substrates synthesized by different templates.

Notes: (A) CTAB, (B) PI23, and (C) PI23 + PPG (I:I)

Abbreviations: SEM, scanning electron microscopy; CTAB, cetyltrimethylammonium bromide; PPG, polypropylene glycol; EHT, extra high tension; WD, working distance.

\section{Publish your work in this journal}

The International Journal of Nanomedicine is an international, peerreviewed journal focusing on the application of nanotechnology in diagnostics, therapeutics, and drug delivery systems throughout the biomedical field. This journal is indexed on PubMed Central, MedLine, CAS, SciSearch $®$, Current Contents ${ }^{\circledR} /$ Clinical Medicine,
Journal Citation Reports/Science Edition, EMBase, Scopus and the Elsevier Bibliographic databases. The manuscript management system is completely online and includes a very quick and fair peer-review system, which is all easy to use. Visit http://www.dovepress.com/ testimonials.php to read real quotes from published authors. 